\title{
The prevalence of social care in US health care settings depends on how and whom you ask
}

\author{
Yuri Cartier ${ }^{*}(\mathbb{D})$ and Laura Gottlieb
}

\begin{abstract}
Background: Despite unprecedented enthusiasm for integrating social risk screening and related interventions into US health care settings, we know relatively little about the extent to which these activities occur. We reviewed results from multiple national surveys that reported on the prevalence of social care activities.

Methods: We used snowball sampling to solicit input from 29 expert informants who were asked to share any knowledge about survey instruments that included questions on the prevalence of social care-related activities conducted in health care settings. We subsequently ran web searches on recommended surveys to identify those fielded with a national sample and conducted between Jan 1, 2007 and May 31, 2019. Finally, we analyzed and compared results across surveys.

Results: We reviewed 23 total survey events (19 individual surveys and 4 that had been re-administered) that included questions on the extent of social care activities across health care disciplines and settings. Samples included a wide range of health care stakeholders (including payers, health care executives, providers, and patients.) Sample sizes ranged across the types of respondents: 95-120 respondents in surveys of payers; 44-757 in surveys of health care delivery leaders; 484-2333 in surveys of clinicians; and 500-7002 in surveys of patients. In eight cases, survey reports did not include response rates; another four reports described response rates under $25 \%$. Fifteen of the 23 surveys incorporated questions on the prevalence of social risk screening; 17 included questions on social care intervention activities. Responses about the prevalence of both screening and interventions varied widely: between 15 and $100 \%$ of respondents reported their organization conducts screening for at least one social risk; $18-100 \%$ of respondents reported providing social care interventions. Between 3 and 22\% of surveyed patients reported being screened or assisted with a social risk. In the four surveys that were administered in different years, we found no significant differences in results between survey administrations.
\end{abstract}

Conclusions: Findings suggest that caution is warranted in interpreting survey findings from any single survey since existing surveys report a wide range of prevalence estimates for social risk screening and interventions.

Keywords: Social determinants of health, Social risk screening, Social care

\footnotetext{
* Correspondence: yuri.cartier@ucsf.edu

Social Interventions Research and Evaluation Network, University of California, San Francisco, UCSF, 3333 California St, Suite 465, San Francisco, CA 94118, USA
}

(c) The Author(s). 2020 Open Access This article is licensed under a Creative Commons Attribution 4.0 International License, which permits use, sharing, adaptation, distribution and reproduction in any medium or format, as long as you give appropriate credit to the original author(s) and the source, provide a link to the Creative Commons licence, and indicate if changes were made. The images or other third party material in this article are included in the article's Creative Commons licence, unless indicated otherwise in a credit line to the material. If material is not included in the article's Creative Commons licence and your intended use is not permitted by statutory regulation or exceeds the permitted use, you will need to obtain permission directly from the copyright holder. To view a copy of this licence, visit http://creativecommons.org/licenses/by/4.0/ The Creative Commons Public Domain Dedication waiver (http://creativecommons.org/publicdomain/zero/1.0/) applies to the data made available in this article, unless otherwise stated in a credit line to the data. 


\section{Background}

Against the backdrop of an increasing number of valuebased care initiatives $[1,2]$ and a strong and compelling body of evidence linking patients' social risks such as food insecurity, housing instability, transportation barriers, or energy insecurity to health outcomes [3-6], it is not surprising that the US health care sector is turning to addressing social risk factors as one component of more comprehensive strategies to improve population health [7-10]. Interest in this area has grown sufficiently to spur a National Academies of Sciences, Engineering, and Medicine (NASEM) Committee on Integrating Social Care into the Delivery of Health Care [11]. Multiple programs at the Centers for Medicare \& Medicaid Services (CMS) and state Medicaid agencies incorporate social risk factor screening and services into care innovations [12, 13]. Consequently, social risk screening tools have proliferated [14], and a new technology industry has emerged to more efficiently bridge medical providers with community and government social services [15].

Despite the unprecedented enthusiasm for integrating social risk screening and related interventions into health care delivery settings, we know relatively little about the extent to which these activities occur around the US. What we currently know about the prevalence of social care is largely derived from papers reflecting the findings of single surveys, typically focused on a particular discipline (e.g. pediatrics) [16] and/or setting (e.g. inpatient care) [17]. These surveys are used in different venues to indicate that social risk screening is either common $[18]$ or rare $[19,20]$ across the health care sector. The validity of these estimates is unknown.

Improved methods for gauging the prevalence of social care activities across disciplines and settings will help target new and pending federal, state, and local policy changes that incentivize social care initiatives, such as emerging state Medicaid agency and Medicare managed care regulatory changes that have increased opportunities to cover social services [21, 22]. We undertook this review of survey results to understand the landscape of existing data on the prevalence of social care activities in health care and to explore strategies for synthesizing data across sources.

\section{Methods}

As part of a broader research project on social riskrelated activities in health care settings, between November 2017 and May 2018 we reached out to 14 experts, including from medical professional associations with published statements on social screening or interventions (the American Academy of Family Physicians and the American Academy of Pediatrics); researchers who had published articles in the academic literature on social care interventions or who had worked on national health surveys; and foundations funding projects on health care sector social care initiatives. Thirteen of the initial 14 agreed to participate in a $30-60 \mathrm{~min}$ semistructured interview. As part of the interview, we asked participants to share information about survey initiatives that had been conducted with health care-affiliated stakeholders (including providers and leaders in organizations that deliver health care services, administer health plans/insurance, and/or provide other services related to medical care) about the prevalence of social risk screening or interventions, or that had asked patients if they had received screening or assistance in their health care setting. We defined health-care based social risk screening as a health care activity related to assessing patients' social circumstances (e.g. food security, housing stability, transportation access). We defined social care interventions as health care-initiated programs or services intended to mitigate or address social risks, either directly (e.g. by offering food or transportation) or indirectly (e.g. by providing assistance with connecting to food benefits programs or supportive housing services). The initial 13 experts were asked to recommend additional informants with expertise in this area. Using this snowball sampling strategy, we spoke with 29 experts, stopping interviews when no new survey initiatives were mentioned by additional informants.

We subsequently ran Google web searches on the 15 surveys mentioned during the 29 interviews to identify surveys that were conducted Jan 1, 2017 or later, were fielded with a national sample, and included questions related to the prevalence of social care activities in the US health care sector. The web searches were used to locate the fielded survey instruments and/or published survey results. We sent email requests to survey-fielding organizations when we were unable to find either full text surveys or a description of survey results online. Both the Health Resources \& Services Administration (HRSA) Bureau of Primary Health Care and the Commonwealth Fund provided full data sets, which enabled us to conduct additional analyses published elsewhere $[23,24]$. We also used references included in published survey results to find additional reports and publications about surveys that met our inclusion criteria. These follow-up searches yielded an additional 29 surveys (Fig. 1). Surveys that were limited to local, regional, or state respondents were excluded. Though our intent was to exclude surveys that had not been conducted with a national sample, included surveys were not required to be nationally representative.

From each included survey, we extracted basic information on survey characteristics, including surveyfielding organization, survey title, year administered, sampling frame, response rate and number of respondents. Additionally, we extracted question text and results 


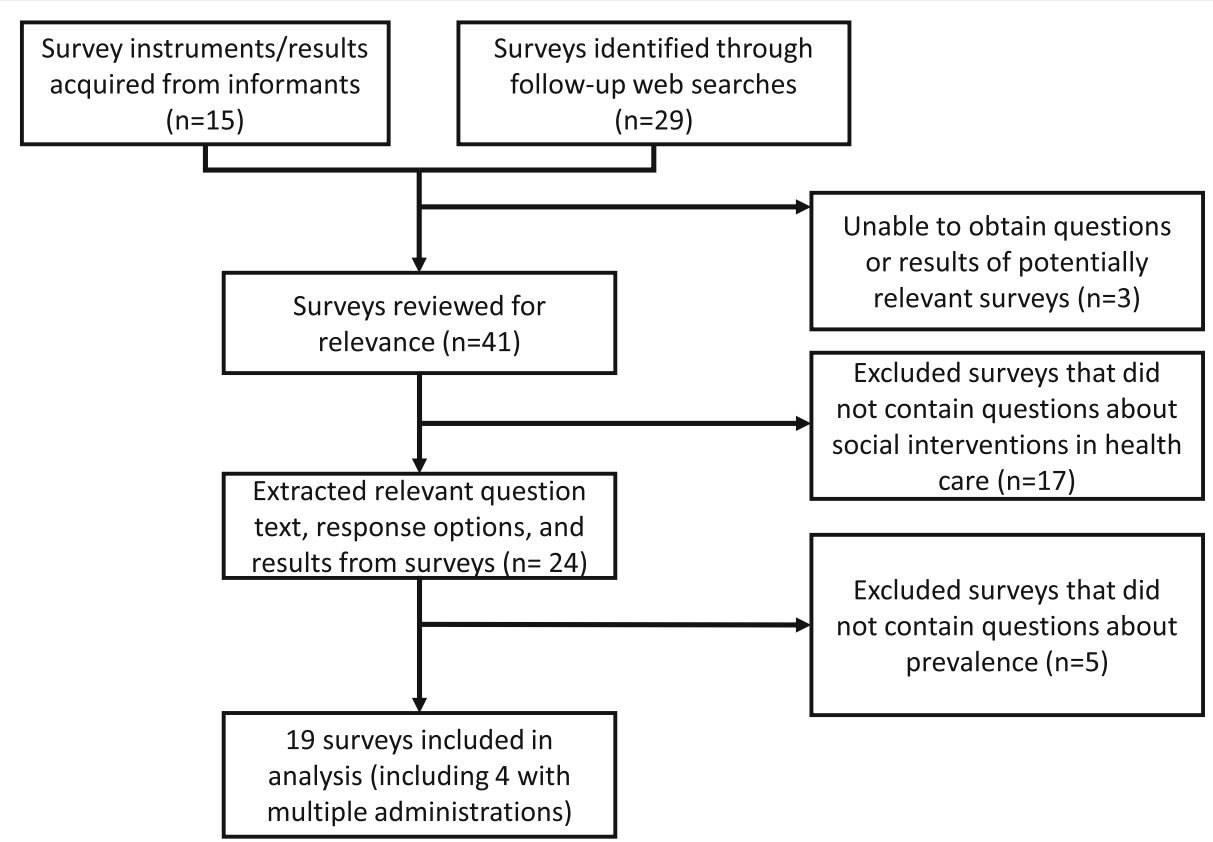

Fig. 1 Diagram of survey identification and inclusion process

for questions pertaining to social care activities. Survey items fell into two clusters: 1. Questions related to screening patients for social risks; and 2. Questions related to providing social services or related interventions. We subsequently excluded surveys that did not include questions about the prevalence of social risk screening or social care-related interventions. Taking into consideration the most frequently-queried social risk domains in included surveys, we compared questions and results in surveys with similar target populations (e.g. patients, clinical providers, etc.) across the five domains included in the CMS Accountable Health Communities health-related social needs screening tool as well as non-domain specific questions. Differences in survey respondents and questions/response options prohibited quantitative pooling of the reported prevalence of these activities. Instead, we conducted a qualitative review of findings across surveys conducted with similar target populations.

\section{Results}

We collected information on 19 surveys that had been conducted across multiple states with groups of health care stakeholders (including state Medicaid agencies, payers, health care executives, providers, and patients) and that incorporated questions about the prevalence of health care-based social risk screening and related social care programs [25]. Table 1 describes the characteristics of the 19 included surveys. Four surveys were administered twice, for a total sample of 23 survey events. Sample sizes ranged across the types of respondents: 95-120 respondents in surveys of payers;
44-757 in surveys of health care delivery leaders, 4842333 in surveys of clinicians, and 500-7002 in surveys of patients.

Seven excluded surveys incorporated questions related to staffing, data collection, or attitudes about social care but did not include questions about the prevalence of screening or interventions. [Information about those surveys is available in Supplemental Table 1]. Fifteen of the 23 surveys included questions about screening activities; 17 included questions about social interventions (nine included questions on both topics).

Information about the frequency of domains included in the survey questions is presented in Supplemental Tables 2 and 3. Compared to surveys including items about social care interventions, surveys that only included items about social risk screening included more detail (i.e., regarding specific social risk domains). Food insecurity was the most commonly included social domain in surveys that included questions about social risk screening $(n=8,53 \%)$; transportation was the most commonly included domain surveys that included questions about social care interventions $(n=8,47 \%)$. The 5 domains used in the CMS Accountable Health Communities Social Needs screening tool were among the most frequently referenced domains overall; employment and education also appeared in approximately one-third of surveys.

\section{Prevalence of social risk screening}

Table 2 presents results from surveys that included a question about the prevalence of social risk screening, e.g. 
Table 1 Surveys on prevalence of social risk screening and/or social care interventions ${ }^{\text {a }}$

\begin{tabular}{|c|c|c|c|}
\hline Category & $\begin{array}{l}\text { Survey-fielding organization (year of } \\
\text { administration) }\end{array}$ & Sample characteristics & Sample size (response rate) \\
\hline \multirow[t]{4}{*}{ Payers } & $\begin{array}{l}\text { Change Healthcare \& HealthCare } \\
\text { Executive Group (2018) [26] }\end{array}$ & $\begin{array}{l}\text { Private payers and healthcare executives } \\
(\mathrm{N}=>2000)\end{array}$ & $\begin{array}{l}n=120 \text { (6\%). Of the respondents, 54\% } \\
\text { represented health plans. }\end{array}$ \\
\hline & $\begin{array}{l}\text { Change Healthcare \& HealthCare } \\
\text { Executive Group (2019) [27] }\end{array}$ & $\begin{array}{l}\text { Private payers and healthcare executives } \\
(\mathrm{N}=>2000)\end{array}$ & Not reported. \\
\hline & $\begin{array}{l}\text { Institute for Medicaid Innovation } \\
\text { (2019) [28] }\end{array}$ & Medicaid Managed Care Organizations & $\begin{array}{l}\text { n not reported, though report describes } \\
\text { that sample represents } 69 \% \text { of Medicaid } \\
\text { managed care covered lives }\end{array}$ \\
\hline & Kaiser Family Foundation (2017) [29] & $\begin{array}{l}\text { Medicaid Managed Care Organizations } \\
(N=277)\end{array}$ & $\begin{array}{l}n=95 \text { plans }(34 \%) \text {, representing } 31 \text { of } \\
39 \text { states. }\end{array}$ \\
\hline \multirow[t]{9}{*}{$\begin{array}{l}\text { Health Care } \\
\text { Delivery Systems }\end{array}$} & $\begin{array}{l}\text { America's Essential Hospitals Essential } \\
\text { Hospitals Institute (2016) [30] }\end{array}$ & $\begin{array}{l}\text { Safety-net hospitals ( } N=108 \text { systems, } \\
\text { representing } 242 \text { hospitals) }\end{array}$ & $\begin{array}{l}n=44 \text { systems (41\%) representing } 109 \\
\text { hospitals (42\%) }\end{array}$ \\
\hline & $\begin{array}{l}\text { American Pediatrics Association Continuity } \\
\text { Research Network (2017) [31] }\end{array}$ & $\begin{array}{l}\text { Pediatric resident continuity clinics } \\
(N=158)\end{array}$ & $n=65(41 \%)$ \\
\hline & Children's Hospital Association (2015) [32] & Children's hospitals $(N=207)$ & $n=73(35 \%)$ \\
\hline & Commonwealth Fund (2013) [33] & FQHCs $(N=1128)$ & $n=679(60 \%)$ \\
\hline & Commonwealth Fund (2018) [34, 35] & FQHCs $(N=1367)$ & $n=694(51 \%)$ \\
\hline & $\begin{array}{l}\text { Dartmouth Institute for Health Policy \& } \\
\text { Clinical Practice }(2018)^{b}[17]\end{array}$ & Hospitals $(N=1628)$ & $n=757(47 \%)$ \\
\hline & $\begin{array}{l}\text { Deloitte Center for Health Solutions } \\
\text { (2017) [36] }\end{array}$ & Hospitals and health systems $(N=4257)$ & $n=284(22 \%)$ \\
\hline & $\begin{array}{l}\text { National Center for Medical-Legal } \\
\text { Partnerships }(2016)[37,38]\end{array}$ & $\begin{array}{l}\text { Health care organizations participating } \\
\text { in MLPs }(N=266)\end{array}$ & $n=128(48 \%)$ \\
\hline & Numerof \& Associates (2018) [39] & $\begin{array}{l}\text { Health care organization executives } \\
(N=9600)\end{array}$ & $n=411(4.3 \%)$ \\
\hline \multirow[t]{6}{*}{ Providers } & $\begin{array}{l}\text { American Academy of Pediatrics } \\
\text { (2014) [16] }\end{array}$ & Pediatricians ( $N=$ approx. 1500) & $n=708(47 \%)$ \\
\hline & $\begin{array}{l}\text { American Association of Family } \\
\text { Physicians (2017) [40] }\end{array}$ & Family physicians $(N=5000)$ & $n=484(10 \%)$ \\
\hline & Commonwealth Fund (2012) [41] & $\begin{array}{l}\text { Primary care physicians in } 11 \text { countries, } \\
\text { including the US }(N=3067)\end{array}$ & 2012: US: $n=1012$ (33\%) \\
\hline & Commonwealth Fund $(2015)[24,42]$ & $\begin{array}{l}\text { Primary care physicians in } 11 \text { countries, } \\
\text { including the US }(N=2567)\end{array}$ & 2015: US: $n=1001$ (39\%) \\
\hline & $\begin{array}{l}\text { Dartmouth Institute for Health Policy \& } \\
\text { Clinical Practice (2018) [17] }\end{array}$ & Physician practices $(N=4976)$. & $n=2333(47 \%)$ \\
\hline & $\begin{array}{l}\text { Leavitt Partners Physician Survey } \\
\text { (2018) [43] }\end{array}$ & Active physicians (N not provided) & $n=550$; response rate unknown \\
\hline \multirow[t]{5}{*}{$\begin{array}{l}\text { Patients/ } \\
\text { Consumers }\end{array}$} & $\begin{array}{l}\text { Health Resources and Services } \\
\text { Administration (HRSA) Bureau of } \\
\text { Primary Health Care (2009) [23] }\end{array}$ & Health center patients ( $\mathrm{N}$ not provided) & $\begin{array}{l}n=4562 \text { patients from } 112 \text { health } \\
\text { centers }\end{array}$ \\
\hline & $\begin{array}{l}\text { HRSA Bureau of Primary Health Care } \\
\text { (2014) [23] }\end{array}$ & Health center patients ( $\mathrm{N}$ not provided) & $\begin{array}{l}n=7002 \text { patients from } 169 \text { health } \\
\text { centers }\end{array}$ \\
\hline & $\begin{array}{l}\text { Leavitt Partners Consumer Survey } \\
\text { (2018) [43] }\end{array}$ & $\begin{array}{l}\text { Adults } 18 \text { or over in the US ( } \mathrm{N} \text { not } \\
\text { provided) }\end{array}$ & $n=5006$; response rate unknown \\
\hline & National Council on Aging (2014) [44] & Older adults ( $\mathrm{N}$ not provided) & $n=3279 ;$ response rate unknown \\
\hline & Waystar (2018) [45] & Consumers (N not provided) & $\mathrm{n}=500$; response rate unknown \\
\hline
\end{tabular}

${ }^{a}$ Four surveys were administered twice-one time/year in two different years. Each administration is listed separately since response rates (and in some cases questions) differed across administrations

${ }^{\mathrm{b}}$ The Dartmouth Institute for Health Policy \& Clinical Practice (2018) survey is listed twice as results were reported separately for hospital/system respondents and physician practice respondents

FQHC Federally Qualified Health Center

"Do you screen your patients for social needs?" Across the 15 survey administrations that included screening prevalence questions, question structure and content both varied. Nine surveys asked about social risk screening generally [26, 27, 29, 32, 37, 38, 40, 45]; eight asked respondents to indicate specific social risk domains included in 
Table 2 Range of respondents reporting social risk screening activities in each survey category

\begin{tabular}{|c|c|c|c|c|c|c|}
\hline & Any social risk & Food & Housing & Transportation & Utilities & IPV \\
\hline \multirow{3}{*}{$\begin{array}{l}\text { Payer surveys } \\
\text { (total } n=4 \text { ) }\end{array}$} & $15 \%[26]$ & $100 \%[28]$ & $100 \%[28]$ & $86 \%[28]$ & $79 \%$ [28] & $86 \%$ [28] \\
\hline & $15 \%[27]$ & & & & & \\
\hline & $91 \%$ [29] & & & & & \\
\hline \multirow{5}{*}{$\begin{array}{l}\text { Health care delivery system surveys } \\
\text { (total } n=7 \text { ) }\end{array}$} & $62 \%[36]$ & $32 \%$ [30] & $50 \%[34]$ & $27 \%$ [30] & $29 \%$ [34] & $46 \%$ [30] \\
\hline & $69 \%$ [32] & $40 \%[17]$ & $57 \%[30]$ & $47 \%[34]$ & $36 \%$ [17] & $49 \%$ [31] \\
\hline & $79 \%$ [38] & $42 \%[34]$ & $60 \%$ [17] & $68 \%$ [36] & $40 \%[36]$ & $57 \%$ [34] \\
\hline & $91 \%$ [17] & $67 \%[36]$ & $70 \%[36]$ & $74 \%$ [17] & & $75 \%$ [36] \\
\hline & & $71 \%$ [31] & & & & $76 \%$ [17] \\
\hline \multirow{2}{*}{$\begin{array}{l}\text { Provider surveys } \\
\text { (total } n=3 \text { ) }\end{array}$} & $59 \%[40]$ & $30 \%$ [17] & $28 \%[17]$ & $35 \%$ [17] & $23 \%$ [17] & $57 \%[17]$ \\
\hline & $67 \%[17]$ & $52 \%[16]$ & $53 \%[16]$ & $68 \%$ [16] & $44 \%$ [16] & \\
\hline $\begin{array}{l}\text { Patient/consumer surveys } \\
\text { (total } n=2 \text { ) }\end{array}$ & $22 \%$ [45] & $6 \%[43]$ & $8 \%[43]$ & $6 \%[43]$ & $4 \%[43]$ & \\
\hline
\end{tabular}

screening activities $[16,17,28,30,31,34,36,43]$. One survey presented screening as an answer option to a question about population health activities [30].

The five social risk domains most commonly included under screening activities were food security, housing stability, transportation access, utility needs, and interpersonal violence. Rates of survey respondents endorsing screening activities in each of these categories across the surveys are presented in Table 2. Only two surveys also reported the overall prevalence of screening for at least one social risk domain. Three surveys that included social risk screening questions included response options about the frequency of screening. In papers about survey results, answer options were typically dichotomized (e.g., any screening vs. no screening; or frequent and sometimes vs. occasional and no screening).

Depending on the survey, between 15\% [26] and 100\% [28] of respondents reported their organization conducts screening for at least one social risk. There were substantial differences in reported prevalence of screening by social risk domain (e.g. food security screening ranged from $30 \%$ [17] to $100 \%$ [28]; transportation access screening ranged from $27 \%$ [30] to $86 \%$ ) [28].

When clustered by category of respondent (e.g. patient, provider, clinic, hospital) results still ranged widely across surveys. For example, in the four hospital or system-level survey administrations reporting on screening for any social risk, the results ranged from 62 [36] to $91 \%$ [17]. Results for food security screening in this group ranged from $32 \%$ [30] to $71 \%$ [31]; for transportation, from $27 \%$ [30] to $74 \%$ [17]; and for IPV, results ranged from $46 \%$ [30] to $76 \%$ [17]. Variability between surveys was lower for screening for housing issues $(50 \%$ [34] to $70 \%$ [36]), and for utility security (ability to pay for utilities) (29\% [34] to $40 \%$ [36]).

Twenty-one of the 23 surveys provided no information about the percent of the total population served who were screened for social risk. Exceptions included one consumer survey that asked patients if their health care provider had discussed social needs with them; $22 \%$ of patients reported that this had occurred in the last 12 months [45]. A second exception was a survey of community health center leaders, which asked about the proportion of the total served patient population that was screened for social needs. In this survey, $40 \%$ of respondents reported screening all patients and $49 \%$ reported screening only some patients [34].

\section{Prevalence of social care interventions}

Table 3 displays the prevalence of intervention activities in the 17 surveys that included questions about the prevalence of social care interventions. Similar to the variation in social risk screening questions, survey questions about interventions differed significantly in content and structure. Some surveys asked about the specific type of intervention provided, such as availability of a database of community social service resources or referrals to social service providers; others asked more generally about any activity that addressed a specific social risk (e.g. interventions around food security). As with the questions about screening, answer options across surveys differed, as did ways responses were dichotomized in reported results.

Depending on the survey, 18 [27]-100\% [28] of respondents indicated that their organization provides social care interventions. The two extreme percentages were reported by the same two payer surveys that reported lowest and highest prevalence of screening. Among surveys conducted in health care delivery systems, overall social care intervention prevalence varied from 52\% [36] to 70\% [39]; in clinical provider surveys, the range was $52 \%$ [40] to $92 \%$ [42]. As in the case of social risk screening, surveyed patients reported significantly lower rates of interventions than 
Table 3 Respondents reporting social intervention activities (including referrals) in each survey category

\begin{tabular}{|c|c|c|c|c|c|c|}
\hline & Any social risk & Food & Housing & Transportation & Utilities & IPV \\
\hline \multirow[t]{3}{*}{ Payer surveys $(n=4)$} & $18 \%[27]$ & $73 \%[29]$ & $77 \%[29]$ & $79 \%[28]$ & $100 \%[28]$ & $79 \%[28]$ \\
\hline & $19 \%[26]$ & $100 \%[28]$ & $100 \%[28]$ & & & \\
\hline & $93 \%[29]$ & & & & & \\
\hline \multirow[t]{3}{*}{ Health care delivery system surveys $(n=5)$} & $52 \%[36]$ & $64 \%[30]$ & $68 \%[30]$ & $31 \%$ [33] & $43 \%[30]$ & $75 \%[30]$ \\
\hline & $54 \%[34]$ & & & $45 \%[34]$ & & \\
\hline & $70 \%[39]$ & & & $61 \%[30]$ & & \\
\hline \multirow[t]{3}{*}{ Provider surveys $(n=5)$} & $52 \%[40]$ & $27 \%[43]$ & $20 \%[43]$ & $35 \%[43]$ & $22 \%[43]$ & $45 \%[43]$ \\
\hline & $91 \%[41]$ & $66 \%[16]$ & $23 \%[16]$ & $50 \%[16]$ & $25 \%[16]$ & \\
\hline & $92 \%[42]$ & & & & & \\
\hline \multirow[t]{2}{*}{ Patient/consumer surveys ( $n=3$ ) } & $19 \%[46]$ & $5 \%[23]$ & $3 \%[23]$ & $10 \%[23]$ & & \\
\hline & & & & $11 \%$ [23] & & \\
\hline
\end{tabular}

providers or health system leaders (19\% among a sample of older adults [46] and between 5 and 11\% of health center patients reporting assistance, depending on the social need [23].)

In the four surveys that included the same questions in repeated administrations (Table 4), there were no statistically significant changes in reported prevalence across administrations. The 15 other surveys either had not been repeated or had not included comparable questions in repeated administrations.

\section{Discussion}

There is no question that the language of social determinants is in vogue in the US health care sector. But how much, where, and when the health care system currently invests in identifying, helping to address, and tracking patients' social risks is unknown. This is the first study of which we are aware that looks across different survey initiatives to estimate the prevalence of social care activities conducted in health care settings. In our review of 19 different surveys and 23 survey events, we found wide variation in reported rates of social risk screening and related interventions.

Differences in the reported frequencies of social risk screening and intervention activities across surveys could stem from true practice variation. For example, Medicaid managed care organization samples reported nearly universal rates of social risk screening and intervention, whereas surveys of mostly private payer samples reported prevalence of social risk activities below $20 \%$. In delivery settings, it is possible that social risk screening is conducted more frequently during hospitalizations than in outpatient community health center settings. It also is conceivable that safety-net hospitals, though they serve more disadvantaged populations, are less likely to have the resources to conduct social risk assessments than betterresourced private hospital facilities. These findings, however, suggest that social care is less likely to be provided to patients more likely to need it.

An alternative explanation is that differences in reported frequencies derive from the challenges of

Table 4 Response trends for survey questions with multiple administrations

\begin{tabular}{|c|c|c|c|c|c|}
\hline Survey name & Question (Definition of positive response) & First administration & $\begin{array}{l}\text { Second } \\
\text { administration }\end{array}$ & Difference & $p^{a}$ \\
\hline Industry Pulse & $\begin{array}{l}\text { How is your organization integrating social determinants of } \\
\text { health into your population health programs? --Coordinating } \\
\text { with community programs and resources (Yes) }\end{array}$ & $19.30 \%(2017)[26]$ & $18.40 \%(2018)[27]$ & $-0.90 \%$ & $0.82^{b}$ \\
\hline $\begin{array}{l}\text { Commonwealth } \\
\text { Fund FQHC }\end{array}$ & $\begin{array}{l}\text { How often do patients at your largest site receive the following } \\
\text { services when they need them: --Transportation (Usually or Often) }\end{array}$ & $48.36 \%(2013)$ [33] & $45 \%(2018)$ [35] & $-3.36 \%$ & 0.21 \\
\hline $\begin{array}{l}\text { Commonwealth } \\
\text { Fund IHPS }\end{array}$ & $\begin{array}{l}\text { Do you and/or other personnel that work with you in your } \\
\text { practice provide care in any of the following ways? } \\
\text { - Coordinate care with social services or other community } \\
\text { providers (2012: Yes; 2015: Frequently or Occasionally) }\end{array}$ & $92.30 \%(2012)[24,41]$ & $91.00 \%(2015)[24,42]$ & $-1.30 \%$ & 0.29 \\
\hline $\begin{array}{l}\text { HRSA Patient } \\
\text { Survey }\end{array}$ & $\begin{array}{l}\text { Has anyone at \{the reference health center\} ever helped you } \\
\text { with transport to medical appointments? (Yes) }\end{array}$ & $10.10 \%$ (2009) [23] & $10.50 \%$ (2014) [23] & $0.40 \%$ & 0.49 \\
\hline
\end{tabular}

${ }^{a}$ Calculated with two-sided $z$ test

${ }^{b}$ We were unable to obtain a sample size for the 2018 Industry Pulse survey; the $p$-value is therefore calculated from a conservative estimate of $300 \%$ of the 2017 sample size

FQHC Federally qualified health center; HRSA Health Resources and Services Administration; IHPS International Health Policy Survey 
designing surveys to adequately capture this information. Only three surveys indicate the reach of social risk screening or interventions by providing an indication of the denominator for patients offered social care services (i.e. total served patients who are screened or who receive services). In other words, survey respondents might endorse having social care programs even if those programs are limited to one setting or even one group of patients, e.g. patients with diabetes attending group visits, rather than available to the entire served population. At the system level, denominators also differ across surveys. For example, the one survey targeting safety-net hospital leaders used skip logic in asking about social risk screening; those who had responded affirmatively to a question about select population health activities were asked the social risk screening question [30]. The lack of a consistent denominator constrains comparisons across surveys.

All of the surveys rely on self-report, in many cases by a single executive responding for an entire organization that may have multiple clinical sites with substantial variations in practice. As a result, it is possible that the reports from patients about their own experiences are a more accurate representation of practice.

Our results highlight common challenges across survey initiatives, underscoring several barriers to using surveys to gauge social care across different settings. Stakeholders interested in any one discipline (e.g. family medicine), population (e.g. older adults), or setting (e.g. community health centers) could-and do-extract findings from the most relevant surveys and critically interpret those findings in light of the limitations of that particular dataset $[16,17]$. Given the gaps in available information and differences across surveys conducted even in similar populations, however, these data are unlikely to be useful for targeting efforts to scale effective programs.

Developing a more accurate and generalizable estimate of the extent to which social care activities-including both screening and interventions-are incorporated into clinical care in the US at minimum will require more standardization in the surveys being used to establish prevalence. This could be facilitated by developing and testing a core set of meaningful and precise survey questions. If survey-sponsoring organizations could achieve consensus on a validated common core of questions, it would improve the reliability and comparability of survey findings. Developing a common core would require deepening a national dialogue about the goals of social screening and social interventions. For example, currently there seems to be no agreement on whether questions about screening should inquire about social screening of any kind occurring in a given setting or screening for specific risks, such as housing or food. Moving forward, initiatives that use surveys to examine trends in screening and intervention adoption over time should include denominator information in survey questions, e.g. by asking about the proportion of the patient population being screened. Given that social care activities related to food, housing, transportation, utilities, and IPV are included in federal demonstration projects and common to many common screening tools, future national surveys on prevalence should consider including these core domains at minimum.

Surveys may not be the most accurate gauge of clinical activities. Another option would be for federal and state agencies to develop and encourage use of documentation standards for social care, including social risk screening, assessment and diagnosis, and treatment/counseling/referrals, in electronic health records. Standardized documentation could strengthen efforts to track these activities and enable data aggregation across systems. To make coding feasible would require overcoming a new set of challenges, such as the availability of accurate codes and incentives around documentation [47, 48]. It is possible that in the near future natural language processing algorithms applied to electronic health records (EHRs) will automate these coding processes by finding relevant information in EHR notes and using that information to standardize documentation [49].

\section{Limitations}

We relied on national key informant experts using snowball sampling to identify survey instruments that attempted to estimate the prevalence of social care in the US health care sector. We selected this method after consulting with an academic librarian and conducting multiple pilot searches of academic databases that did not adequately surface relevant publications. Our search strategy enabled us to include surveys where findings were not intended for academic or other publication. It is nonetheless possible that informants were unfamiliar with relevant surveys. Additionally, in some cases, neither the survey questions nor results were yet available to include in this synthesis. There is no reason to assume the common limitations we found in the study sample (e.g. low sample size, low response rates, respondent bias) would be overcome in other surveys, though if considering a common question core across future survey initiatives, it would be appropriate to review survey questions from all available sources. Lastly, we did not include regional or state-specific surveys, nor did publications on included surveys conduct regionspecific analyses. This precluded us from identifying potential geographic variability in social risk screening or social care intervention practices. 


\section{Conclusions}

There is wide variation in the results of surveys intended to gauge the prevalence of social care provided in US health care settings. As the health care sector debates new investments in this area, more careful attention should focus on how to estimate program depth and breadth. Only then can we understand the effectiveness of policy and practice incentives that aim to scale social care programs.

\section{Supplementary information}

Supplementary information accompanies this paper at https://doi.org/10. 1186/s12913-020-05338-8.

Additional file 1: Supplemental Table 1. Surveys excluded from analysis. Supplemental Table 2. Number of surveys that include questions about screening for social (and behavioral) risks.

Supplemental Table 3. Number of surveys that include questions about interventions related to social (and behavioral) risks.

\section{Abbreviations}

CMS: Centers for Medicare \& Medicaid Services; EHR: Electronic health record; FQHC: Federally qualified health center; HRSA: Health Resources \& Services Administration; IHPS: International Health Policy Survey; MLP: Medical-legal partnership; NASEM: National Academies of Sciences, Engineering, and Medicine; US: United States

\section{Acknowledgements}

We acknowledge Angeli Bueno, Emilia De Marchis, Caroline Fichtenberg, Matthew Pantell, Evans Whitaker, and Holly Wing for their contributions to the review. The key informants and surveying organizations are also gratefully acknowledged.

\section{Authors' contributions}

YC contributed to study design, conducted informant interviews, collected and analysed survey data, and was a major contributor to the manuscript. LG designed the study, conducted informant interviews, oversaw survey data collection, analysed data, and was a major contributor to the manuscript. All authors read and approved the final manuscript.

\section{Funding}

We acknowledge the Robert Wood Johnson Foundation for funding this review and for suggesting potential informants and surveys for inclusion. The funder did not play any other role in the design of the study and collection, analysis, and interpretation of the data or in writing the manuscript.

\section{Availability of data and materials}

The datasets used and/or analyzed during the current study are available from the corresponding author on reasonable request.

\section{Ethics approval and consent to participate}

This research study was certified as exempt research by the University of California, San Francisco Institutional Review Board (study reference 1723359). Per UCSF IRB guidance regarding exempt research, verbal or implied consent is usually sufficient for exempt research. Each key informant gave verbal consent to participate. Consent was recorded in a spreadsheet accessible only to the study team.

\section{Consent for publication}

Not applicable.

\section{Competing interests}

The authors declare that they have no competing interests.
Received: 8 January 2020 Accepted: 18 May 2020

Published online: 29 May 2020

\section{References}

1. Alderwick H, Hood-Ronick CM, Gottlieb LM. Medicaid investments to address social needs in Oregon and California. Health Aff. 2019:38(5):774-81. https://doi.org/10.1377/hlthaff.2018.05171.

2. Change Healthcare. Value-Based Care in America: State-by-State.; 2019.

3. Baer TE, Scherer EA, Fleegler EW, Hassan A. Food insecurity and the burden of health-related social problems in an urban youth population. J Adolesc Health. 2015;57(6):601-7. https://doi.org/10.1016/j.jadohealth.2015.08.013.

4. Sandel M, Sheward R, Ettinger de Cuba S, et al. Timing and Duration of Preand Postnatal Homelessness and the Health of Young Children. Pediatrics. 2018;142(4). https://doi.org/10.1542/peds.2017-4254.

5. Gundersen C, Ziliak JP. Food insecurity and health outcomes. Health Aff. 2015;34(11):1830-9. https://doi.org/10.1377/hlthaff.2015.0645.

6. Hernández D. Understanding 'energy insecurity' and why it matters to health. Soc Sci Med. 2016. https://doi.org/10.1016/j.socscimed.2016.08.029.

7. Beck AF, Cohen AJ, Colvin JD, et al. Perspectives from the Society for Pediatric Research: interventions targeting social needs in pediatric clinical care. Pediatr Res. 2018;84(1):10-21. https://doi.org/10.1038/s41390-018-0012-1.

8. Gottlieb LM, Wing $H$, Adler NE. A systematic review of interventions on patients' social and economic needs. Am J Prev Med. 2017:53(5):719-29. https://doi.org/10.1016/j.amepre.2017.05.011.

9. Gottlieb L, Fichtenberg C, Adler N. Screening for social determinants of health. Jama. 2016:316(23):2552. https://doi.org/10.1001/jama.2016.16915.

10. Gottlieb L, Fichtenberg C, Alderwick H, Adler N. Social determinants of health: What's a healthcare system to do? J Healthc Manag. 2019;64(4):24357. https://doi.org/10.1097/JHM-D-18-00160.

11. The National Academies of Sciences Engineering and Medicine. Integrating Social Needs Care into the Delivery of Health Care to Improve the Nation's Health. http://nationalacademies.org/hmd/activities/healthservices/ integratingsocialneedscareintothedeliveryofhealth caretoimprovethenationshealth.aspx. Accessed 26 Aug 2019.

12. Alley DE, Asomugha CN, Conway PH, Sanghavi DM. Accountable health communities - addressing social needs through medicare and medicaid. N Engl J Med. 2016;374(1):8-11. https://doi.org/10.1056/NEJMp1512532.

13. Center for Medicare \& Medicaid Innovation. Comprehensive Primary Care Plus. 2019. https://innovation.cms.gov/initiatives/comprehensive-primarycare-plus. Accessed 27 Nov 2019.

14. Andermann A. Screening for social determinants of health in clinical care: moving from the margins to the mainstream. Public Heal Rev. 2018;39:19. https://doi.org/10.1186/s40985-018-0094-7.

15. Cartier Y, Fichtenberg C, Gottlieb LM. Community Resource Referral Platforms: A Guide for Health Care Organizations. San Francisco: Social Interventions Research and Evaluation Network; 2019.

16. Garg A, Cull W, Olson L, et al. Screening and referral for low-income families' social determinants of health by US pediatricians. Acad Pediatr. 2019. https://doi.org/10.1016/j.acap.2019.05.125.

17. Fraze TK, Brewster AL, Lewis VA, Beidler LB, Murray GF, Colla CH. Prevalence of screening for food insecurity, housing instability, utility needs, transportation needs, and interpersonal violence by US physician practices and hospitals. JAMA Netw Open. 2019;2(9):e1911514. https://doi.org/10. 1001/jamanetworkopen.2019.11514.

18. Prevalence of screening for social needs. ScienceDaily. https://www. sciencedaily.com/releases/2019/09/190918113618.htm. Accessed 26 Dec 2019.

19. Lewis R. Few Physicians Screen for Social Determinants of Health. Medscape. 2019. https://www.medscape.com/viewarticle/918640. Accessed Dec 262019.

20. Cheney C. Screening for social determinants of health limited at Healthcare organizations. HealthLeaders Media https://www.healthleadersmedia.com/ clinical-care/screening-social-determinants-health-limited-healthcareorganizations. Accessed 26 Dec 2019.

21. Barr P, Dickson V. CMS may allow hospitals to pay for housing through Medicaid. Modern Healthcare. 2018. https://www.modernhealthcare.com/ article/20181114/NEWS/181119981. Accessed 14 Dec 2018.

22. United States Congress. Bipartisan Budget Act of 2018. Pub.L. 115-123.

23. De Marchis EH, Pantell MS, Fichtenberg C, Gottlieb LM. Prevalence of patient-reported social risk factors and receipt of assistance in federallyfunded health centers. J Gen Intern Med. 2020;35(1):360-64. https://doi.org/ 10.1007/s11606-019-05393-w. 
24. Pantell MS, De Marchis E, Bueno A, Gottlieb LM. Practice capacity to address patients' social needs and physician satisfaction and perceived quality of care. Ann Fam Med. 2019;17(1):42-5. https://doi.org/10.1370/afm.2334.

25. Social Interventions Research and Evaluation Network. National Surveys Gauging Prevalence of Social Care-Related Activities in the Health Care Sector. 2018. https://sirenetwork.ucsf.edu/node/19671.

26. Change Healthcare. The 8th annual industry pulse report. Change Healthcare; 2018.

27. Change Healthcare. The 9th Annual Industry Pulse Survey.; 2019.

28. Moore JE, Adams C, Tuck K. 2019 Annual Medicaid MCO Survey; 2019.

29. Garfield R, Hinton E, Cornachione E, Hall C. The Kaiser Family Foundation 2017 survey of Medicaid managed care plans. Menlo Park; 2018.

30. Ramiah K, Roberson B, Schrag J, Susman K, Siegel B, White M. Population health at essential hospitals: findings from moving to action for hospitals and population health; 2016.

31. Morgenlander MA, Tyrrell H, Garfunkel LC, Serwint JR, Steiner MJ, Schilling S. Screening for social determinants of health in pediatric resident continuity clinic. Acad Pediatr. 2019. https://doi.org/10.1016/j.acap.2019.02.008.

32. Children's Hospital Association. Population Health and Children's Hospitals: National Survey Findings.; 2015.

33. Commonwealth Fund. The 2013 Commonwealth Fund National Survey of Federally Qualified Health Centers. 2013. https://www.commonwealthfund. org/publications/surveys/2014/may/2013-commonwealth-fund-nationalsurvey-federally-qualified-health. Accessed 2 Aug 2019.

34. Commonwealth Fund. 2018 FQHC Survey Topline (unpublished) 2019

35. Lewis C, Coleman A, Abrams MK, Doty MM. The role of Medicaid expansion in care delivery at community health centers. Washington, D.C.: Commonwealth Fund; 2019.

36. Lee J, Korba C. Social determinants of health: how are hospitals and health systems investing in and addressing social needs? 2017.

37. Theiss J, Regenstein M. Facing the need: screening practices for the social determinants of health. J Law, Med Ethics. 2017;45(3):431-41. https://doi. org/10.1177/1073110517737543.

38. Regenstein M, Sharac J, Trott J. The state of the medical-legal partnership field: findings from the 2015 National Center for medical-legal partnership surveys. Washington, D.C.: National Center for Medical-Legal Partnership; 2016.

39. Numerof \& Associates. The State of Population Health : Third Annual Numerof Survey Report.; 2018.

40. American Academy of Family Physicians. 2017 Social Determinants of Health Survey:; 2017.

41. Commonwealth Fund. 2012 Commonwealth Fund international survey of primary care doctors. 2012. https://www.commonwealthfund.org/ publications/surveys/2012/nov/2012-commonwealth-fund-internationalsurvey-primary-care-doctors. Accessed 2 Aug 2019.

42. Commonwealth Fund. 2015 Commonwealth Fund international survey of primary care physicians in 10 nations. 2015. https://www.commonwealthfund. org/publications/surveys/2015/dec/2015-commonwealth-fund-internationalsurvey-primary-care-physicians. Accessed 2 Aug 2019.

43. Edwards K, Kornbluth R, Muhlestein D. Taking Action on Social Determinants of Health; 2019.

44. National Council on Aging. United States of Aging Survey: 2015 Results. 2015. https:/www.ncoa.org/news/resources-for-reporters/usoa-survey/2015-results/

45. Waystar. Consumer Perspectives on How Social Determinants Impact Clinical Experience.; 2018.

46. National Council on Aging. United States of Aging Survey: 2014 Results. https://www.ncoa.org/uncategorized/usoa-survey/archive/\#intraPageNav0. Accessed 27 Aug 2019.

47. Arons A, DeSilvey S, Fichtenberg C, Gottlieb L. Documenting social determinants of health-related clinical activities using standardized medical vocabularies. JAMIA Open. 2019;2(1):81-8. https://doi.org/10.1093/ jamiaopen/ooy051.

48. Gottlieb L, Tobey R, Cantor J, Hessler D, Adler NE. Integrating social and medical data to improve population health: opportunities and barriers. Health Aff. 2016;35(11):2116-23. https://doi.org/10.1377/hlthaff.2016.0723.

49. Conway M, Keyhani S, Christensen L, et al. Moonstone: a novel natural language processing system for inferring social risk from clinical narratives. J Biomed Semant. 2019;10(1):6. https://doi.org/10.1186/s13326-019-0198-0.

\section{Publisher's Note}

Springer Nature remains neutral with regard to jurisdictional claims in published maps and institutional affiliations.

Ready to submit your research? Choose BMC and benefit from:

- fast, convenient online submission

- thorough peer review by experienced researchers in your field

- rapid publication on acceptance

- support for research data, including large and complex data types

- gold Open Access which fosters wider collaboration and increased citations

- maximum visibility for your research: over $100 \mathrm{M}$ website views per year

At $\mathrm{BMC}$, research is always in progress.

Learn more biomedcentral.com/submissions 